\title{
Pemberdayaan Taman Pendidikan Al-Quran (TPA) Sebagai Pusat Pendidikan Karakter Religus (Pengabdian di TPQ Silastra Condong Catur,TPQ Darul Falah Maguwo Harjo Maguwo Harjo, TPA Al-Huda Caturtunggal,Yogyakarta)
}

\author{
Yayuk Hidayah ${ }^{1}$, Suyitno ${ }^{2}$, Lisa Retnasari ${ }^{3}$ \\ 1,2,3Pendidikan Guru Sekolah Dasar (PGSD), Universitas Ahmad Dahlan \\ Yogyakarta \\ Email:1yayuk.hidayah@pgsd.uad.ac.id, 22suyitno@pgsd.uad.ac.id, \\ 3lisa.retnasari@pgsd.uad.ac.id
}

\begin{abstract}
The service partner is the TPQ Silastra Condong Catur, Darul Falah TPQ Maguwo Harjo Maguwo Harjo, TPA Al-Huda Caturtunggal, Yogyakarta. The reason for determining the proposed object problem is the background of the problems that arise in the lack of use of the Al-Quran Education Park (TPA) as the center of religus character education. The solution proposed by the dedication team was to integrate the Al-Quran reading and writing learning with the values of religious characters to the santri. The method used by the service team is consultation, mentoring, and training. The contribution proposed by the dedication team is for TPA to maximize the role of TPA in religious character education. For santri, they can get additional knowledge. For the community, they can support the efforts to cultivate religious character education. The conclusion is that the existence of TPA is still essential in society as a place of education for children.
\end{abstract}

Keywords: TPQ, Character Religious, Empowerment

\section{Pendahuluan}

Kebutuhan masyarakat faktual dan aktual dalam pengabdian pemberdayaan Taman Pendidikan Al-Quran (TPA) sebagai pusat pendidikan karakter religus merupakan salah satu upaya solutif yang tim lakukan dengan berdasarkan bahwa Taman Pendidikan Al-Quran (TPA) masih eksis di masyarakat sebagai tempat pendidikan agama bagi anak. Metode pembiasaan, cerita, demonstrasi, nasihat, dan keteladanan merupakan metode yang digunakan pengajar di TPQ Al-Amin Pabuwaran Purwokerto 
Utara Banyumas dalam pembinaan karakter religius santri. ${ }^{1}$

Implementasi metode pembelajaran Al Qura'an di TPQ An-Nahdliyah Al Falah Banjar Parakan Rawalo, banyumas terdapat tiga bagian yaitu bagian awal, inti dan penutup yang secara umum semuanya salang berkiatan. ${ }^{2} \mathrm{Di}$ Malaysia, Sentralisasi administrasi dan kurikulum semua sekolah yang menawarkan semacam pendidikan Islam telah mendominasi upaya Kementerian Pendidikan di bidang pendidikan Islam formal. Kurikulum telah dirancang untuk mencapai tujuan Filsafat Pendidikan Islam. Ada upaya terusmenerus untuk mengakhiri dualisme antara pendidikan sekuler dan keagamaan. ${ }^{3}$

Pendidikan Islam dan agama memiliki sejarah panjang di Malaysia, Malaysia dapat membangun dan berurusan dengan Sekolah-sekolah Islam dan kurikulum agama setelah melakukan percobaan kurikulum secara intensif. ${ }^{4}$ Pembelajaran agama juga ada dalam kurikulum di sekolah secara formal, Namun, kita hampir tidak tahu bagaimana mereka membuat kemajuan pada subjek ini dan apa pentingnya partisipasi mereka dalam subjek ini sebenarnya. ${ }^{5}$ Dengan melibatkan 174 para guru pendidikan agama di sekolah-sekolah Rumania. Hasil penelitian menunjukan bahwa pendidikan agama muncul sebagai dimensi/komponen penting pendidikan dengan efek penting pada kesehatan moral bangsa, dan sebagai faktor pengaruh kesejahteraan manusia.

${ }^{1}$ Bari, M. F. Pembinaan Religiusitas Santri Di Taman Pendidikan Al-Qur'an (TPQ) AlAmin Pabuaran Purwokerto Utara Banyumas Tahun Pelajaran 2014/2015, 2015.

${ }_{2}$ Masrukhin. Implementasi Metode Pembelajaran Al Qur'an di TPQ An-Nahdliyah Al Falah Desa Banjarparakan Kecamatan Rawalo Kabupaten Banyuma., 2016

${ }^{3}$ Fauzi, A., \& Hamid, A., Islamic Education in Malaysia Islamic Education in Malaysia. In Handbook ofIslamic Education, International Handbooks of Religion and Education (pp. 0-17). 2018

${ }^{4}$ Karimizadeh, N., \& Abolghasemi, M. The Islamic and Religious Education in Malaysian Schools: From Past Up to Now Introduction: International Academic Journal of Innovative Research, 3(4), 19-29, 2016.

${ }^{5}$ Itulua-abumere, F., Social, H., \& Agency, S. The Significance of Religious Education in Local Primary Schools (Specific Reference to Christianity) The Significance of Religious Education in Local Primary Schools (Specific Reference to Christianity). IOSR Journal Of Humanities And Social Science (IOSR-JHSS), (January). 2014. 
Berdasarkan permasalahan-permasalahan tersebut, maka tim pengabdian melakukan pengabdian masyarakat dengan judul "Pemberdayaan Taman Pendidikan Al-Quran (TPA) Sebagai Pusat Pendidikan Karakter Religus (Pengabdian di TPQ Silastra Condong Catur, TPQ Darul Falah Maguwo Harjo Maguwo Harjo, TPA Al-Huda Caturtunggal, Yogyakarta)" selama bulan Mei 2018 - Desember 2018.

Pendidikan Al-Quran telah melewati perkembangan yang cukup Panjang dalam sejarah. Taman Pendidikan Al-Quran (TPA) mempunyai banyak sebutan baik TKA, TKQ, TPQ, TQA. Dewasa ini, Taman Pendidikan alQuran (TPQ) menjadi pendidikan luar sekolah yang enekankan pada pengajaran AL Qu'an dan pembentukan akhlak qurani.6 Taman pendidikan alQur'an merupakan jawaban kebutuhan akan pembelajaran baca tulis AL Qu'an selain di sekolah, Perubahan secara cepat dihadapi anak zaman sekarang mulai dari sosial, politik hingga lingkungan. ${ }^{7}$

Kebutuhan baca tulis Al Qur'an menjadi kebutuhan sehingga kehadiran Taman pendidikan al-Qur'an dapat menjadi alternatif kebutuhan tersebut (Kusuma, 2018). ${ }^{8}$ Dalam pengabdian yang dilakukan oleh tim, setidaknya ada beberapa masalah, persoalan, tantangan, untuk mewujudkan pemberdayaan Taman Pendidikan Al-Quran (TPA) sebagai pusat pendidikan karakter religius yaitu sebagai berikut:

1) Belum maksimalnya pemberdayaan Taman Pendidikan Al-Quran (TPA) sebagai pusat pendidikan karakter religus

2) Urgensi pendidikan karakter religus khususnya di usia dini

Taman Pendidikan Al-Quran (TPA) hanya fokus pada pembelajaran baca tulis Al-Quran

6 Ajhuri KF, S. M. Pemberdayaan Taman Pendidikan Al-Quran (TPQ) melalui. Qalamuna, 10(2), 2018, 175-195.

${ }^{7}$ Ulfa, Z. Roses Penanaman Nilai-Nilai Moral Pada Anak Di Tpq Muhammadiyah Kelurahan Mangkang Wetan Kecamatan Tugu Kota Semarang. Semarang: Universitas Negeri Semarang, 2014

${ }^{8}$ Kusuma, Y. Model-Model Perkembangan Pembelajaran BTQ di TPQ /TPA. 2018 


\section{Metode}

Lokasi pengabdian berada di 3 (tiga) Taman Pendidikan Al-Quran yaitu TPQ Silastra Condong Catur, TPQ Darul Falah Maguwo Harjo Maguwo Harjo, TPA Al-Huda Caturtunggal, Yogayakarta. Waktu dan durasi pengabdian dilaksanan Mei-Desember 2018. Adapun durasi waktu pengabdian sebagai berikut.

Tabel 1. Durasi waktu pengabdian

\begin{tabular}{|c|c|l|}
\hline No & \multicolumn{1}{|c|}{ Durasi } & \multicolumn{1}{c|}{ Lokasi } \\
\hline 1 & Mei-Desember 2018 & $\begin{array}{l}\text { TPQ Silastra Condong Catur, } \\
\text { Yogyakarta }\end{array}$ \\
\hline 2 & Mei-Desember 2018 & $\begin{array}{l}\text { TPA Al-Huda Caturtunggal, } \\
\text { Yogyakarta }\end{array}$ \\
\hline 3 & Mei-Desember 2018 & $\begin{array}{l}\text { TPQ Darul Falah Maguwo Harjo Maguwo } \\
\text { Harjo, Yogyakarta }\end{array}$ \\
\hline
\end{tabular}

Sumber: Dokumentasi Pengabdian, 2018

\section{Hasil dan Diskusi}

\section{Pemberdayaan Taman Pendidikan Al-Quran (TPA) Sebagai Pusat Pendidikan Karakter Religius}

Untuk mewujudkan Taman Pendidikan Al-Quran (TPA) sebagai pusat pendidikan karakter religus tim pengabdian melakuakan simulasi IPTEK guna memperkenalkan karakter religius secara menyenangkan pada santri. Pemberdayaan tim tekankan guna memaksimalkan keberadaan Taman Pendidikan Al-Quran (TPA) yang masih esksis di masyarakat motivasi intrinsik, ekstrinsik, dan darurat merupakan motivasi yang ada dalam wali murid dalam memanfaatkan Taman Pendidikan Al-Quran (TPA) sebagai wadah pendidikan selain sekolah bagi wali murid.9 Dengan lokasi di TPQ Silastra Condongcatur, TPQ Darul Falah Maguwo Harjo Maguwo Harjo, TPA

\footnotetext{
${ }^{9}$ Mudmainah, N. Motivasi Wali Murid Memasukkan Anaknya di TPQ Al- Anwar Desa Dadapayam Kecamatan Suruh, Semarang Tahun 2013/2014, 2014
} 
Al-Huda Catur tunggal, Yogyakarta tim dapat secara berangsur memanfaatkan peran Taman Pendidikan Al-Quran (TPA) dalam memaksimalkan pendidikan karakter religius.
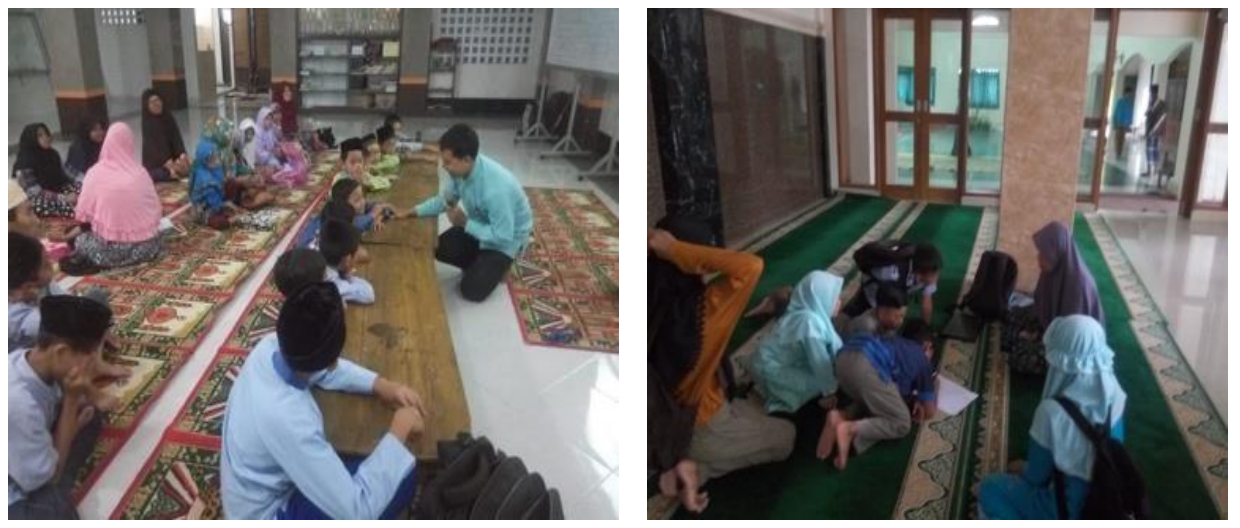

Gambar 1. Pemberdayaan Taman Pendidikan Al-Quran (TPA) Sebagai Pusat Pendidikan Karakter Religius (Sumber: Dokumentasi oleh tim pengabdian, 2018)

\section{Urgensi Pendidikan Karakter Religus Khususnya Di Usia Dini}

Pendidikan karakter religius sejak dini perlu dikenalkan guna melakukan penanaman konsep terhadap anak mengenai karakter religius. Lahirnya generasi yang memiliki kualitas merupakan haraoan dari pengenalan pendidikan karekter sejak sini. ${ }^{10}$ Untuk mewujudkan hal ini, tim pengabdian dalam pelaksaan melakukan merode konsultasi guna menjaring informasi dan konfirmasi permasalahan dari pengurus Taman Pendidikan AlQuran (TPA) dan masyarakat. Dapat merubah perilaku, merupakan harapan lainnya dari penananman budi pekerti pada anak usia dini. 11Dalam melakukan konsultasi, tim pengabdian dapat melakukan beberapa pemecahan masalah antara lain yaitu:

${ }^{10}$ Billah, A. Dalam Materi Sains Arif Billah Abstrak. Kan Karakter Untuk Anak Usia Dini... (Arif Billah) Attarbiyah, Journal of Islamic Culture and Education, I(2), 2016, hal 243272 .

11 Kusrahmadi, S. D. Pentingnya Pendidikan Budi Pekerti Bagi Anak Usia Dini. Yogyakarta. 2010. 
1) Bagi Taman Pendidikan Al-Quran (TPA)

Taman Pendidikan Al-Quran (TPA) dapat mengintegrasikan pembelajaran dengan memasukan nilai-nilai pendidikan karakter religius, selain itu pembiasaan di lingkungan Taman Pendidikan AlQuran (TPA) juga dapat terlaksana secara berkala.

2) Bagi pengurus Taman Pendidikan Al-Quran (TPA)

Pengurus Taman Pendidikan Al-Quran (TPA) dapat secara berkala menyusun silabus yang kekinian dan sesuai dengan kebutuhan masyarakat, selain itu pengurus juga memperoleh pelatihan dan pendampingan untuk mewujudkan peran Taman Pendidikan Al-Quran (TPA) sebagai pendidikan karakter religious.

3) Bagi masyarakat

Selama pengabdian berlangsung, masyarakat dapat secara bertahap memahami bahwa pendidikan karakter religius membutuhkan dukungan dari kelurga. Selain itu, kini masyarakat juga dapat memanfaatkan keberadaan Taman Pendidikan Al-Quran (TPA) sebagai alternative Lembaga pendidikan selain sekolah untuk dapat menumbuhkan karakter religius kepada anak.

\section{Simpulan}

Setelah melakukan pengabdian, kesimpulan yang dapat tim pengabdian dapat yaitu.

1. Ketepatan atau kesesuaian antara masalah/persoalan terhadap metode yang diterapkan oleh tim adaalah tepat untuk persoalan pemberdayaan Taman Pendidikan Al-Quran (TPA) sebagai pusat pendidikan karakter religus

2. Dampak dan manfaat kegiatan pengabdian terbagi menjadi tiga (3) yaitu bagi santri dapat memperoleh pengetahuan dan penguatan pendidikan 
karakter religius, bagi pengajar dapat dengan maksimal memanfaatkan Taman Pendidikan Al-Quran (TPA) sebagai pusat pendidikan karakter religus. Bagi masyarakat dapat mendapatkan jawaban atas persoalan pendidikan karakter religius yang penting ditumbuhkan sejak dini.

3. Rekomendasi untuk kegiatan pengabdian kepada masyarakat berikutnya, agar dapat memanfaatkan Taman Pendidikan Al-Quran (TPA) secara efisien

\section{Daftar Referensi}

Ajhuri KF, S. M. (2018). Pemberdayaan Taman Pendidikan Al-Quran (TPQ) melalui Qalamuna, 10(2), 175-195.

Bari, M. F. (2015). Pembinaan Religiusitas Santri Di Taman Pendidikan AlQur'an (Tpq) Al-Amin Pabuaran Purwokerto Utara Banyumas Tahun Pelajaran 2014/2015. Purwokerto: Sekolah Tinggi Agama Islam Negeri.

Billah, A. (2016). Dalam Materi Sains Arif Billah Abstrak. Kan Karakter Untuk Anak Usia Dini... (Arif Billah) Attarbiyah, Journal of Islamic Culture and Education, I(2), 243-272. https://doi.org/10.18326/attarbiyah.v1i2.

Fauzi, A., \& Hamid, A. (2018). Islamic Education in Malaysia Islamic Education in Malaysia. In Handbook of Islamic Education, International Handbooks of Religion and Education (pp. 0-17). https://doi.org/10.1007/978-3319-53620-0

Itulua-abumere, F., Social, H., \& Agency, S. (2014). The Significance of Religious Education in Local Primary Schools (Specific Reference to Christianity) The Significance of Religious Education in Local Primary Schools (Specific Reference to Christianity). IOSR Journal Of Humanities And Social Science (IOSR-JHSS), (January). https://doi.org/10.9790/0837-0666994

J-PAI: Jurnal Pendidikan Agama Islam, 5(1), 46-58. Mariana, R., \& Norel, M. (2013). Religious education an important dimension of human ' $\mathrm{s}$ education. Procedia - Social and Behavioral Sciences, 93, 338-342. https://doi.org/10.1016/j.sbspro.2013.09.200

Karimizadeh, N., \& Abolghasemi, M. (2016). The Islamic and Religious Education in Malaysian Schools: From Past Up to Now Introduction : International Academic Journal of Innovative Research, 3(4), 19-29. 
Kusrahmadi, S. D. (2010). Pentingnya Pendidikan Budi Pekerti Bagi Anak Usia Dini. Yogyakarta.

Kusuma, Y. (2018). Model-Model Perkembangan Pembelajaran BTQ di TPQ / TPA.

Masrukhin. (2016). Implementasi Metode Pembelajaran Al Qur'an di TPQ AnNahdliyah Al Falah Desa Banjarparakan Kecamatan Rawalo Kabupaten Banyumas. Purwokerto: institut Agama Islam Negeri (IAIN).

Mudmainah, N. (2014). Motivasi Wali Murid Memasukkan Anaknya di TPQ AlAnwar Desa Dadapayam Kecamatan Suruh, Semarang Tahun 2013/2014.

Surakarta: Universitas Muhammadiyah Surakarta.

Ulfa, Z. (2014). Roses Penanaman Nilai-Nilai Moral Pada Anak Di Tpq Muhammadiyah Kelurahan Mangkang Wetan Kecamatan Tugu Kota Semarang. Semarang: Universitas Negeri Semarang. 